\title{
Apresentação
}

\section{O almanaque: dos periódicos oitocentistas ao Facebook}

The almanac: from nineteenth-century periodicals to Facebook

\section{DoI}

https://doi.org/10.37508/rcl.2021.n46a473

Em pleno século XXI, quando a rede mundial de computadores, provedores de acesso, servidores e outros componentes que permitem a comunicação virtual entre todos, com acesso a numerosas fontes de informação, atinge públicos cada vez maiores e mais diversificados, poderá parecer estranho a publicação de um dossiê centrado num gênero textual e editorial que, à primeira vista, parece marginal e decrépito. Todavia os almanaques, cujas semelhanças com a produção textual da Internet estão a exigir estudos profundos e diversificados, continuam a ser publicados por toda a parte, com tiragens que ultrapassam frequentemente as de livros e jornais. Acrescente-se ainda que o almanaque não é uma forma única, imutável e de cariz exclusivamente popular, interessando mais do que se poderia pensar à história da cultura e, em particular, à da literatura. No universo cultural luso-brasileiro, recorde-se, por exemplo, o Al- 
manak das Musas que, editado em Lisboa no final do século XVIII, engloba a produção poética dos árcades da Academia de Belas Letras ou Nova Arcádia e que tem como principais méritos a reunião do maior conjunto de autores portugueses do seu tempo e a revelação da faceta erudita do poeta luso-brasileiro Domingos Caldas Barbosa, que nele desempenhou papel fundamental.

Não é consensual a definição do objeto almanaque $e^{1}$ que para Roger Chartier (2001) é um "gênero" simultaneamente editorial e literário. Na mesma linha, Ernesto Rodrigues (1999) considera que ele realiza a fusão do jornal, da revista e do livro, pois reúne notícias do presente, memórias do passado e anotações prospectivas relacionadas com o ano vindouro, além de passatempos e criações literárias. Por sua vez, Lise Andries (1996) o vê como um manual prático de consulta diária, frequentemente oferecido como presente de Ano Novo. Em contrapartida, Nelson de Almeida (1995), para quem o almanaque é apenas uma forma característica da literatura de cordel ou da paraliteratura, não consegue dar conta da variedade/dualidade das suas características, visto que há almanaques populares e eruditos, bem ou mal concebidos, utilitários ou de divertimento, baratos e caros, destinados a um público especializado, portanto reduzido, ou a públicos amplos e diversificados, portadores de ideologia conservadora ou de ideias esclarecidas e reformadoras. Tal multiplicidade é posta em evidência nas seguintes afirmações de Jacques Le Goff:

1 A origem do substantivo "almanaque" também não encontra consenso entre os investigadores que apontam ora o árabe almanakh, ora o baixo latim almanachus, ora o baixo grego almanakon. Manuel Viegas Guerreiro e João David Pinto Correia (1986) lembram que os Romanos possuíam tabuinhas polidas, onde registravam fatos relativos às quatro estações, às festas fixas e ao curso das constelações e que tabuinhas semelhantes eram utilizadas pelos Escandinavos por volta do século VI ou VII. 
Ilustrado, com signos, figuras, imagens, o almanaque dirige-se aos analfabetos e a quem lê pouco. Reúne e oferece um saber para todos: astronômico, com os eclipses e as fases da Lua; religioso e social, com as festas e especialmente as festas dos santos, que dão lugar aos aniversários no seio das famílias; científico e técnico, com conselhos sobre os trabalhos agrícolas, a medicina, a higiene; histórico, com as cronologias, os grandes personagens, os acontecimentos históricos ou anedóticos; utilitário, com a indicação das feiras, das chegadas e partidas dos correios; literário, com anedotas, fábulas, contos; e, finalmente, astrológico. (LE GOFF, 1994, p. 518).

Referido no dicionário digital de Caldas Aulete como "publicação que traz um calendário completo, com datas históricas, feriados, fases da lua etc., além de textos humorísticos e literários e matéria informativa", o almanaque provém de tempos imemoriais, tendo recebido diversas designações, tais como anuário, calendário, repertório, lunário, prognóstico, efemérides, folhinha, guia de forasteiros, borda-d'água perfeito lavrador. Indicadores do movimento dos astros, seus ancestrais eram oferecidos pelos astrólogos das cortes orientais aos reis como objetos preciosos e chegaram ao Ocidente, na Idade Média, através de astrólogos árabes, judeus ou cristãos-novos.

Produzidos, a princípio, por homens de ciência² e lidos por eruditos, navegadores, médicos e outros cientistas, tais escritos iniciaram um progressivo alargamento de assuntos e de público com o aparecimento da imprensa. Como anotam Manuel Viegas Guerreiro e João David Pinto Correia, os almanaques, em função do público a que se destinavam, ou continuaram a ser

2 De exemplo serve o Almanach Perpetuum do médico e filósofo Abraão Zacuto, que foi traduzido para o português por José Vizinho e editado em Leiria, em 1496. 
um pequeno folheto, dirigido à população rural e dos arredores das cidades, ou, então, aumentar(am) o número de páginas, tornando-se um instrumento de divulgação de conhecimentos quer para um público geral, mais burguês e citadino, quer junto de algumas camadas sociais diferenciadas por ideários políticos, religiosos ou por outros interesses muito específicos (GUERREIRO; CORREIA, 1986, p. 49).

Sem abdicar da sua função inicial de prognóstico, os almanaques acompanharam o alargamento do universo da alfabetização e a necessidade de oferta de "literatura" para públicos específicos ${ }^{3}$ e não obrigatoriamente populares, entre as quais a de informação rápida e sintética em vários campos, a de divertimento ou de intervenção. Assim, alguns deles passaram a abordar questões políticas, a incluir matérias literárias e jocosas, bem como diversos tipos de passatempo. Ilustrações e apresentação gráfica atraente indiciam a função pedagógica deste tipo de publicação, cujo sucesso é incontestável no plano comercial e na eficácia do que transmite.

Se a periodicidade anual pode ser apontada como traço comum à maior parte dos almanaques, a sua extensão varia das tradicionais oito folhas dos folhetos de cordel a centenas de páginas, que podem incluir imagens variadas. Seu formato e sua encadernação, adaptados às suas funções informativas e sociais, refletem, segundo Margarida Cunha (2002), o gosto, o estilo e a posição social de quem os produz e adquire.

Com raízes nos calendários da Antiguidade mas modificados profundamente com o passar dos tempos, os almanaques atingiram o apogeu no século XIX. Tendo se tornado um verdadeiro fenômeno

3 Entre esses contam-se almanaques que, destinados em particular a cozinheiros, publicam, como é óbvio, um conjunto de receitas e de outros textos relacionados com a culinária. 
editorial, aumentaram em número, em espécies e em tiragens, em consonância com o enorme crescimento dos seus leitores, produzindo aquilo a que se chamou, depreciativamente, "cultura de almanaque”. Divergindo, porém, dos que os vêem como fontes de preconceitos e de superstição, Maria Carlos Radich afirma que

ao percorrer uma colecção, mesmo incompleta, de almanaques, colhe-se a impressão de ir desdobrando as pregas de uma sociedade multifacetada, de lidar com um caleidoscópio que a cada pequena passagem apresentasse um novo quadro de gentes, de géneros, de interesses e de gostos e que aos poucos fosse tracejando, mesmo se caótico e esfarrapado, um fresco social (RADICH, s/d, p. 8).

Na segunda metade do século XIX, os almanaques haviam conseguido incontestável importância e expansão, tanto em Portugal como no Brasil. Segundo Ernesto Rodrigues (1999), em Portugal contavam-se vinte almanaques em 1868 e quarenta e sete em 1873. Por esses anos e nos seguintes, eles são tão lidos e numerosos em Lisboa que Alberto Pimentel chega a considerá-los uma "epidemia” (apud RODRIGUES, 1999). Por sua vez, Manuel Viegas Guerreiro e João David Pinto Correia (1986) referem que a intelectualidade portuguesa (e em nosso entender também a brasileira) passou a reconhecer os benefícios desse produto editorial e, em particular, a possibilidade de atingir um público mais vasto, com isso contribuindo para o desenvolvimento cultural da nação e para o interesse pela literatura.

Dentre os almanaques que, na segunda metade do século XIX e início do século XX, gozaram de incontestável importância no espaço cultural luso-brasileiro, a supremacia cabe ao Almanaque de Lembranças, cuja existência foi invulgarmente longa, visto que foi lançado em 1850, tendo a sua última edição a data de 1931, e cujas tiragens excederam os vinte mil exemplares, acrescidos, em alguns anos, por reedições. Este sucesso deveu-se não só às características e méritos da obra, mas ainda a baixos preços de venda, a promoções na 
compra dum conjunto de volumes e a facilidades na sua aquisição no Brasil. Como assinalou Eliana de Freitas Dutra (2005) na década de 1880 , o preço dum exemplar equivaleria, no Brasil, ao de meio quilo de café ou ao de um quilo de açúcar.

Concebido por intelectuais, este anuário, de caráter urbano, enquadra-se no subgrupo dos almanaques literários, pois, além do calendário do ano vindouro, de informações práticas e da divulgação de conhecimentos muito variados, apresenta vasto conjunto de passatempos e composições literárias de autores de diferentes épocas e proveniências. Em formato de livro de bolso, ele costura, como num patchwork, textos redigidos, adaptados, transcritos ou traduzidos pelos editores junto com outros que lhes eram enviados por colaboradores anônimos ou não. Completavam a obra muitas ilustrações mais ou menos relacionadas com os textos que secundavam: mapas e logradouros de cidades, reprodução de edificações, monumentos, palácios, esboços e retratos de figuras históricas, artistas, escritores, quadrinhos humorísticos, etc.

Lançada para o ano de 1851 por Alexandre Magno de Castilho4, a coletânea teve pouco depois o seu título alargado para Almanaque de Lembranças Luso-Brasileiro' devido ao particular interesse daquele renomado intelectual português em estabelecer um forte relacionamento com o Brasil. Tendo formulado votos, para que o

4 A Alexandre Magno de Castilho (1850-1860) - irmão do renomado escritor romântico Antônio Feliciano de Castilho -, seguiram-se o seu sobrinho, também chamado Alexandre Magno de Castilho (1861-1871); António Xavier Rodrigues Cordeiro (1872-1897); António Xavier de Sousa Cordeiro (1898-1903); Adriano Xavier Cordeiro (1904- 1916; O. Xavier Cordeiro (1917-1931); e Armando de Lima Pereira, responsável apenas pelo último volume e o único que não estaria ligado aos anteriores por laços de parentesco.

5 Título que, mantido de 1874 a 1871, foi substituído por Novo Almanaque de Lembranças Luso-Brasileiro, a partir do volume para o ano de 1872. As transcrições do almanaque foram atualizadas em conformidade com o Acordo ortográfico de 1990. 
seu anuário criasse "um nexo mais" entre portugueses e seus irmãos brasileiros, estreitando e fortificando "os vínculos de sangue que mutuamente nos prendem" (CASTILHO, ALLB 1856, p. 27), Castilho considera ultrapassados "os dias de mal cabidos ciúmes, que pareciam tornar inimigas duas nações que por tantos títulos, e por todos, se deviam amar" e anuncia que o almanaque, a partir "do seu segundo lustro, ser(ia) impresso em duas edições ao mesmo tempo - a de Portugal e a do Brasil" e que "Comuns no fundo estas duas edições só diferir(iam) nas cláusulas propriamente de calendário, para servirem com igualdade aos interesses de ambos os países" (CASTILHO, ALLB 1855, p. 30) ${ }^{6}$.

Tão grande era a popularidade da coletânea no Brasil que o editor dirigiu primeiramente aos brasileiros o seguinte agradecimento:

Aos nossos irmãos d'além mar agradecemos o muito que por sua parte hão contribuído para que este Almanaque justifique a denominação que tomou de Luso-Brasileiro. (...) A quantos num e noutro hemisfério nos coadjuvam por qualquer modo em nossa tarefa (que durará em quanto se lhe conserve o público favor, de que trataremos de tornar-nos sempre dignos), agradecemos do íntimo do coração, onde lhe fica levantado o padrão de nosso reconhecimento. (CASTILHO, ALLB 1858, p. 18)

Posicionado firmemente na defesa das ligações, da história e da cultura comum de Portugal e da sua antiga colônia sul-americana, o Almanaque de Lembranças publicou numerosíssimas matérias sobre o Brasil e acolheu vasta colaboração brasileira. De Machado de Assis, por exemplo, foram publicados dois fragmentos em prosa ("O delírio" e "A borboleta preta") e seis poemas, dois deles por duas vezes ("O verme", "Coração triste falando ao sol”, "A amante

6 Não foi possível confirmar se tal solução se manteve, a partir deste volume, em toda a coletânea. 
de Camões", "Circulo vicioso", "Quando ela fala" e "A mosca azul”). Ignora-se, contudo, se o próprio Machado teria enviado aos editores algum(ns) daqueles textos ou se a decisão de publicá-los terá partido do organizador dos volumes em que aparecem.

Sem desviar-se do caminho aberto pelo seu criador, o Almanaque de Lembranças foi-se tornando mais volumoso: de cerca de cem páginas, no primeiro número, passou a mais de quinhentas em anos posteriores. Ampliou e diversificou as suas matérias que, de início e à semelhança doutras publicações do mesmo tipo, restringiam-se ao calendário português, com o signo correspondente a cada mês, e a informações de cariz religioso (santos do dia, comemorações e prescrições da Igreja), social e econômico (festas nacionais, natalícios da família real portuguesa e da família imperial brasileira, feiras e mercados, tarifas dos comboios e correios, câmbios, etc), passando a incluir passatempos, poemas, prosa literária e informativa, perfil biobibliográfico de figuras ilustres, às quais se prestava homenagem, além do elenco dos colaboradores e da sua correspondência com o editor e de anúncios. A multiplicidade de assuntos foi ambição assumida por Castilho já no primeiro volume ao afirmar que

difícil fora encerrar em tão diminuto quadro, mais vasta coleção de apontamentos em todos os ramos dos conhecimentos humanos. Apontamentos, é a palavra própria. O que só pretendi foi publicar um livrinho ameno, próprio para todos os paladares, e de inegável utilidade, ao mesmo tempo para todas as classes. As pessoas instruídas folgarão de recordar-se; as outras acharão bastante que aprender, e em todo o caso um estímulo a sua curiosidade (CASTILHO, ALLB 1851, p. s/no).

Tendo gozado de enorme popularidade e importância no seu tempo, o Almanaque de Lembranças foi um dos mais interessantes fenómenos de comunicação escrita e de divulgação da cultura da segunda metade do século XIX e início do século XX, no espaço lusófono, 
e que mais do que qualquer outro impresso permitiu assegurar o "trânsito atlântico", que ainda hoje mantêm Portugal, o Brasil e os demais Países da CPLP.

Tal como em muitos outros países, em Portugal e no Brasil, o interesse pelos almanaques se manteve no século XX. Em Portugal, comprova-o o Almanaque Bertrand, que, editado desde 1899 até 1970, reunia, em cerca de 400 páginas, um conjunto de calendários, que não ocupavam mais de cinquenta páginas, a uma longa seção literária, científica e recreativa formada por passatempos, enigmas, anedotas, contos, curiosidades e provérbios. No Brasil do início do Novecentos, a enorme popularidade dos almanaques é referida por Cláudia Neves Lopes (2003), ao assinalar que a tiragem de um almanaque podia atingir trinta ou cem mil exemplares, enquanto a de um livro ficava-se então por seiscentos ou oitocentos exemplares, chegando a dois mil quando era um best seller. O Brasil e a Índia se destacam atualmente como grandes produtores do gênero, talvez porque neles ainda exista considerável grau de analfabetismo. Roberto Câmara Benjamim (2003) conta que Vicente Vitorino de Melo e José Costa Leite fizeram, no Nordeste brasileiro, em 2000 uma primeira tiragem de seus almanaques com mil exemplares e que face ao êxito das suas vendas preparavam-se para duplicá-la. Em Portugal, no ano 2005, a Editorial Minerva indica ter feito uma tiragem de cento e cinquenta mil exemplares do almanaque Borda d’Água.

Daí se poder pensar, com Jean-Yves Mollier, que o almanaque constitui "une sorte de phénix de l'imprimerie moderne" (MOLLIER, 2003, p.13), uma vez que, apesar dos sinais de declínio da sua trajetória, a força de renovação e de adaptabilidade que manifestou ao longo dos últimos cinco séculos, denota uma capacidade de contínuo renascimento e desafia qualquer possibilidade de extinção em futuro próximo. Diante de tal vitalidade, julgou-se oportuno revisitar esse produto cultural com novos olhares, compondo o dossiê da presente Convergência Lusíada. 
Dos seis textos que aqui lhe são dedicados, nenhum dispensa a retomada da controvertida gênese, ou de aspectos das metamorfoses desse gênero tão pertinaz, como preâmbulo das abordagens selecionadas por seus autores, as quais se estendem por Portugal, França, Brasil, Angola e o indelimitável espaço da web.

Assim, Ernesto Rodrigues, cujo ensaísmo à volta do tema é notório, em "Almanaque: composição de um rosto", amplia estudos anteriores e detém-se no fenômeno da sua incalculável disseminação, graças à heteróclita audiência angariada, sobretudo no século XIX. Examina os "vários dispositivos impressos (que) concorrem na sua configuração", com destaque para a publicidade, e conclui com um olhar sobre a firme circulação internacional desses periódicos: "aceitemos as ligações atlânticas da rede postal luso-afro-brasileira via almanaque como anúncio do moderno Facebook."

Já Dirceu Magri, em “De Almanach a Almanak: um olhar sobre dois importantes almanaques", sublinha o interesse recente de pesquisadores sobre esse "gênero", traça-lhe breve cronologia e tipologia e, a seguir, detém-se no exame do palaciano Almanach Royal, criado na França em 1683, que tomará diversos nomes e feições e perdura ainda na atual era do blog. Em seguida, examina atentamente o Almanak Laemmert, publicado no Rio de Janeiro a partir de 1844, que se tornou um ícone dessa produção periódica. Confirmado o caráter essencialmente fragmentário comum a todos os almanaques, emergem considerações sobre a dialética "dissolução da totalidade, justamente por querer buscá-la a todo custo”.

Por sua vez, João Luís Lisboa, em "Duelo à Lua - o Sarrabal contra o Cego, cerca de 1740", opta por trazer à ribalta duas personagens imaginárias de cariz jocoso que circulam pela produção setecentista dos almanaques portugueses a ponto de, metonimicamente, os designarem: o Sarrabal Saloyo e o Cego Astrólogo disputam acirradamente a preferência do público. 
Alargando geografias, Francisco Soares, em "Os almanaques e a literatura em Angola no século XIX”, efetua precioso inventário comentado da produção e dos autores almanaquianos oitocentistas nessa "província ultramarina", bem como lhes rastreia a interlocução com o emblemático Almanach de Lembranças.

Do século XX luso-brasileiro, Maria Aparecida Ribeiro, no original "Manuel Bandeira e Carlos Drummond de Andrade: poetas de almanaque?", recupera os esquecidos almanaques dirigidos pelo poeta modernista Alberto de Serpa, editados no Portugal dos anos 50, e investiga os intercâmbios que levaram à inclusão em suas páginas de poemas de Bandeira e Drummond.

Encerrando o dossiê, Luciana Salles e Marlon Barbosa, em "Nômades digitais: em busca de comunidades, do almanaque às redes sociais", constatam, nas várias modalidades de comunicação instantânea que a internet disseminou, a permanência, sob o volátil invólucro digital, de formas, conteúdos e propósitos agregadores que caracterizam o longevo e camaleônico almanaque.

A subsequente seção da revista colige quatro ensaios de temas diversos, a começar pelo de Irene Fialho, "De França para o Brasil - a Literatura Portuguesa a agradecer", no qual, com base num artigo assinado por Mariano Pina na carioca Gazeta de Notícias, e aqui transcrito, são trazidas a público "informações relevantes, esclarecedoras de fatos desconhecidos da vida e da obra de Eça de Queirós”.

Leonardo Mendes e Aline Moreira, em "Alfredo Gallis (1859-1910), pequeno naturalista", fazem emergir a figura de um fecundo polígrafo, em prosa e verso, que as histórias da literatura portuguesa apagaram, apesar do sucesso angariado junto ao leitores da Belle Époque luso-brasileira e atribuem seu obscurecimento à mal-vista abordagem de temas ditos pornográficos, comuns na estética naturalista.

Em “"O primeiro 'repórter' feminino do Rio de Janeiro”: Virginia Quaresma no Brasil", Eduardo da Cruz e Andreia de Castro resgatam 
alguns "aspectos profissionais, feministas e políticos" menos divulgados, a partir de pesquisa documental sobre a atuação e recepção desta escritora "portuguesa, negra, que mantinha relações amorosas com outras mulheres" no Brasil do início do século XX.

Finalizando a seção, Luis Antonio Contatori Romano, em "Itinerários líricos por Ouro Preto em revistas do Estado Novo português e brasileiro: Mário de Andrade, Carlos Drummond de Andrade, Henriqueta Lisboa e Cecília Meireles", revisita as publicações Atlântico: Revista Luso-Brasileira e Travel in Brazil para, de suas páginas, destacar a focalização da cidade de Ouro Preto nas palavras dos prestigiados escritores brasileiros, as quais, de certo, incentivaram o turismo histórico-literário e medidas de preservação do seu patrimônio.

Das três resenhas que completam esta Convergência Lusíada, duas enfocam publicações decorrentes do projeto de estudo e divulgação da produção de autoria feminina no Almanaque de Lembranças | Almanaque de Lembranças Luso-Brasileiro | Novo Almanaque de Lembranças Luso-Brasileiro, anuários circulantes de 1850 a 1932 nos países lusófonos, que transcorre no CLEPUL - Centro de Literaturas e Culturas Lusófonas e Europeias da Faculdade de Letras da Universidade de Lisboa - e já trouxe à luz outros títulos. Assim, Susana Vieira aprecia detidamente o volume Amélia Janny 1842-1914. Estudo, Antologia e Bibliografia, organizado por Maria Aparecida Ribeiro, que disponibiliza ao leitor amplo conhecimento da vida e obra da escritora coimbrã, que se tornou um emblema da cidade, enaltecida por Castilho e outros ilustres contemporâneos. De igual modo, Ana Lisboa de Mello examina o volume Narcisa Amália: 1852-1924. Estudo, antologia e bibliografia, organizado por Anna Faedrich, dedicado à escritora nascida no Rio de Janeiro, que "publicou um único livro em vida: a reunião de poemas intitulada Nebulosas, editada em 1872, pela Garnier e não custeada pela autora", que, na altura, contava apenas 20 anos.

Por fim, Alvaro Santos Simões Junior analisa a nova edição de Portugal d'agora, de João do Rio, com introdução, organização e notas 
de Sílvia Maria Azevedo e Tania Regina de Luca. Obra fundamental na trajetória do autor, cujo centenário de falecimento se rememora neste 2021, marca o fim do "localismo" carioca que o levara à Academia Brasileira de Letras e inaugura, com esses registros da sua primeira viagem à Europa na primeira década do século XX, uma fase em que se mostra "consciente da conveniência de fortalecer e ampliar os vínculos afetivos, editoriais e culturais entre brasileiros e portugueses", assumindo "uma perspectiva cosmopolita que veio a coincidir com os interesses e ideologia de uma elite carioca em processo de franca europeização cultural".

Pelo exposto, uma palavra de agradecimento aos colaboradores deste número da Convergência Lusíada e um convite ao público para que percorra as suas páginas, na esperança de grande proveito a quem as ler.

\section{Vania Pinheiro Chaves}

Centro de Literatura e Culturas Lusófonas e Europeias (CLEPUL) / Faculdade de Letras - Universidade de Lisboa

Gilda Santos

Universidade Federal do Rio de Janeiro (UFRJ), Real Gabinete Português de Leitura (RGPL) / Polo de Pesquisas Luso-Brasileiras (PPLB)

\section{REFERÊNCIAS}

ALMEIDA, Nelson. "Almanaque”. In: Biblos. Enciclopédia Verbo das Literaturas de Língua Portuguesa v. 1. Lisboa/São Paulo: Editorial Verbo, 1995.

ANDRIES, Lise. "Almanaques - revolucionando um gênero tradicional". In: DARNTON, Robert; ROCHE, Daniel (orgs.). A revolução impressa: a imprensa em França, 1775-180o. São Paulo: EdUSP, 1996.

AULETE, Caldas. Dicionário da Língua Portuguesa on line. https://www. aulete.com.br/dicionario. Acesso em: 11 de janeiro de 2021. 
BENJAMIM, Roberto Câmara. "L'Almanach de Cordel aujourd'hui, Information et éducation populaires. In: LUSEBRINK, Hans-Jurgen (org). Les lectures du peuple en Europe et dans les Amériques du XVII au XXe siècle. Bruxelas: Complexe, 2003, p. 193-199.

CASTILHO, Alexandre Magno (ed.). Almanach de Lembranças para 1851.2 ed. Lisboa, Imprensa de Lucas Evangelista, 1853.

CASTILHO, Alexandre Magno (ed.). Almanach de Lembranças Luso-Brasileiro para 1855. Lisboa, Imprensa de Lucas Evangelista, 1854.

CASTILHO, Alexandre Magno (ed.). Almanach de Lembranças Luso-Brasileiro para 1856. Lisboa, Typographia Universal, 1855 .

CASTILHO, Alexandre Magno (ed.). Almanach de Lembranças Luso-Brasileiro para 1858. Lisboa, Imprensa Nacional, 1857.

CHARTIER, Roger. “Textos, impressão, leituras”. In: HUNT, Lynn (org.). A Nova História Cultural. 3 ed. SP: Martins Fontes, 2001.

CUNHA, Margarida. “A encadernação dos almanaques”. In: GALVÃO, Rosa Maria (coord.). Os sucessores de Zacuto. O almanaque na Biblioteca Nacional do século XV ao XXI. Lisboa: Biblioteca Nacional, 2002, p. 25-27.

DUTRA, Eliane de Freitas. "Laços fraternos". Revista do Arquivo Público Mineiro. Belo Horizonte, dez. 2005, p. 117-127.

GUERREIRO, Manuel Viegas; CORREIA, João David Pinto. "Almanaques ou a Sabedoria e as Tarefas do Tempo". Revista do Instituto de Cultura e Língua Portuguesa no 6. Lisboa: ICALP, ago/dez 1986, p. 43-52.

LE GOFF, Jacques. História e memória. Campinas: UNICAMP, 1994.

LOPES, Cláudia Neves. “L'Almanaque Brasileiro Garnier: simple transfer culturel ou adaptation d'un genre européen au Nouveau Monde? In: LUSEBRINK, Hans-Jurgen (org.). Les lectures du peuple en Europe et dans les Amériques du XVII e au XXe siècle . Bruxelas: Complexe, 2003, p. 185-192.

MOLLIER, Jean-Yves. "Introduction”. In: LUSEBRINK, Hans-Jurgen (org.). Les lectures du peuple en Europe et dans les Amériques du XVII au $\chi \chi^{e}$ siècle. Bruxelas: Complexe, 2003, p. 11-14.

RADICH, Maria Carlos. Almanaque, tempos e saberes. Coimbra: Centelha, s. d..

RODRIGUES, Ernesto. "Espaços alternativos". In: Cultura literária oitocentista. Porto: Lello, 1999. 